\title{
Recuperação e reutilização do carbonato de propileno empregado no processo de extração de poli(3-hidroxibutirato)
}

\section{Recovery and reuse of propylene carbonate used in the process of poly(3-hydroxybutyrate) extraction}

\author{
Luci Kelin de Menezes Quines ${ }^{1}$, Melodi Schmidt ${ }^{1}$, Kellen Zanfonato', Francielli Manenti Martinhago ${ }^{1}$, \\ Willibaldo Schmidell ${ }^{1}$ e Gláucia Maria Falcão de Aragão1*
${ }^{1}$ Departamento de Engenharia Química e Engenharia de Alimentos, Universidade do Federal de Santa Catarina - UFSC, Florianópolis, SC, Brasil
*glaucia.aragao@ufsc.br

\begin{abstract}
Resumo
A extração de poli(3-hidroxibutirato) $(\mathrm{P}(3 \mathrm{HB}))$ com a utilização de solventes tóxicos e voláteis é contraditória à ideia do emprego destes biopolímeros para minimizar as agressões ambientais causadas pelos polímeros petroquímicos. $\mathrm{O}$ carbonato de propileno $(\mathrm{CP})$ possui baixa toxicidade e alto ponto de ebulição, o que garante baixo risco de perdas por evaporação e alto rendimento de recuperação, podendo assim ser reutilizado. O objetivo deste trabalho foi verificar o efeito da reutilização do $\mathrm{CP}$, recuperado do processo de extração de $\mathrm{P}(3 \mathrm{HB})$ produzido por Cupriavidus necator, no rendimento e pureza do biopolímero e avaliar as perdas de solvente durante as etapas do processo de extração. Verificou-se a possibilidade de recuperar $80 \%$ do $\mathrm{CP}$ ao longo do processo. O solvente recuperado foi reutilizado onze vezes sem perder sua eficiência no rendimento e na pureza do produto. Desta forma, o presente estudo propõe a reutilização do $\mathrm{CP}$, no processo de extração de $\mathrm{P}(3 \mathrm{HB})$, contribuindo assim para a redução dos custos de produção deste biopolímero.
\end{abstract}

Palavras-chave: poli(3-hidroxibutirato), extração, recuperação, reutilização, carbonato de propileno.

\begin{abstract}
Poly(3-hydroxybutyrate) $(\mathrm{P}(3 \mathrm{HB}))$ extraction using toxic volatile solvents is contradictory to the idea of using this biopolymer to minimize environmental aggressions caused by petrochemical polymers. Propylene carbonate (PC) has low toxicity and high boiling point, which ensure a low risk of losses due to evaporation and high recovery performance, allowing for reuse. The aim of this study was to investigate the effect of reusing PC recovered the process of extraction of $\mathrm{P}(3 \mathrm{HB})$ produced by Cupriavidus necator on the performance and purity of the biopolymer and evaluate the amount of solvent loss during the stages of the extraction process. It was observed that $80 \%$ of PC could be recovered throughout the process. The recovered solvent was reused eleven times without losing its efficiency in terms of product performance and purity. Hence, the present study proposes to reuse $\mathrm{PC}$ in the process of $\mathrm{P}(3 \mathrm{HB})$ extraction, thus contributing to reduce the costs for the production of this biopolymer.
\end{abstract}

Keywords: poly(3-hydroxybutyrate), extraction, recovery, reuse, propylene carbonate.

\section{Introducão}

Os poli-hidroxialcanoatos (PHAs) são biopolímeros, biocompatíveis e biodegradáveis, produzidos intracelularmente como reserva de carbono e energia por muitos microrganismos, a partir de recursos renováveis ${ }^{[1]}$. Entre os PHAs, o poli(3-hidroxibutirato) $(\mathrm{P}(3 \mathrm{HB}))$ é o biopolímero mais visado em estudos acadêmicos. No entanto, seu uso comercial é limitado devido às técnicas de produção e extração serem bastante dispendiosas ${ }^{[2,3]}$.

Por se tratar de um produto intracelular, o $\mathrm{P}(3 \mathrm{HB})$ deve ser extraído da célula ao término do cultivo e estima-se que o impacto do custo de extração deste biopolímero, no custo total do processo de produção, possa representar mais de $50 \%$ do valor final do produto ${ }^{[4]}$. Os métodos utilizados no processo de extração de $\mathrm{P}(3 \mathrm{HB})$ são: extração por solventes orgânicos como clorofórmio ${ }^{[5]}$; carbonato de propileno ${ }^{[6,7]}$; dicloroetano $^{[8]}$; digestão enzimática ${ }^{[9,10]}$; métodos mecânicos ${ }^{[1,12]}$ e o uso de soluções aquosas de surfactantes e quelantes ${ }^{[13,14]}$. Dentre estes, os que fazem uso de solventes são os mais extensivamente utilizados. No entanto, o uso de solventes tóxicos e altamente voláteis para a extração de $\mathrm{P}(3 \mathrm{HB})$ (por exemplo, clorofórmio) é contraditório ao fato de que estes polímeros vêm sendo amplamente estudados para 
minimizar as agressões ambientais causadas pelos polímeros de origem petroquímica ${ }^{[7,15]}$.

De acordo com Mcchalicher et al. ${ }^{[16]}$, o solvente ideal para a extração de biopolímeros de microrganismos a pressões atmosféricas deve ser capaz de dissolver os PHAs abaixo da temperatura de degradação do polímero, minimizando a degradação da cadeia polímérica, ser reutilizável e apresentar baixos riscos ambientais. Neste contexto, a extração de $\mathrm{P}(3 \mathrm{HB})$ com carbonato de propileno foi primeiramente proposta por Lafferty e Heinzle ${ }^{[17]}$, como alternativa aos solventes clorados. Propylene carbonate (PC), segundo a IUPAC (International Union of Pure and Applied Chemistry), recebe a nomenclatura de 4-metil-1,3-dioxolan-2-ona, sendo um éster de ácido carbônico cíclico e apresenta propriedades interessantes como não persistir no meio ambiente porque é degradado e não é genotóxico, ou seja, não causa danos aos genes de uma célula ou de um organismo ${ }^{[18,19]}$.

Embora haja preocupação sobre a presença de residuais provenientes dos solventes nos biopolímeros, o carbonato de propileno já foi aprovado para uso em aplicações sensíveis, tais como cosméticos e medicamentos ${ }^{[16]}$. Estudos têm demonstrado que o carbonato de propileno não é facilmente absorvido através da pele, podendo ser utilizado em uma variedade de cosméticos em concentrações de até $5 \%{ }^{[18]}$.

Na Tabela 1 estão apresentados os valores de dose letal $50\left(\mathrm{DL}_{50}\right)$, definida como a quantidade de uma substância química que, quando administrada em uma única dose via oral expressa em massa de substância por massa de animal (rato), produz a morte de $50 \%$ dos mesmos, dentro de um período de observação. Esta tabela evidencia o grau de toxicidade de alguns dos solventes reportados na literatura para a extração de PHAs.

Como pode ser observado, dentre os solventes apresentados na Tabela 1, o carbonato de propileno é o que apresenta maior valor de $\mathrm{DL}_{50}$ em ratos, evidenciando sua baixa toxicidade frente aos outros solventes utilizados para extração de PHAs. O carbonato de propileno apresenta a desvantagem de alto custo, no entanto, possui elevado ponto de ebulição, próximo a $240{ }^{\circ} \mathrm{C}$, permitindo que o risco de perda por evaporação seja baixo, podendo ainda ser reutilizado diversas vezes, minimizando os custos de produção de PHAs ${ }^{[16]}$.

Frente ao exposto, o objetivo do presente trabalho foi verificar a eficiência da reutilização do carbonato de

Tabela 1. $\mathrm{DL}_{50}$ aguda (ratos-via oral) para alguns solventes empregados no processo de extração de PHAs a partir de microrganismos

\begin{tabular}{lc}
\hline \multicolumn{1}{c}{ Solvente } & $\mathbf{D L}_{\mathbf{5 0}}\left(\mathbf{m g ~ \mathbf { ~ g } ^ { - 1 }}\right)$ \\
\hline Carbonato de propileno & 20700 \\
Clorofórmio & 908 \\
Hipoclorito de sódio & 8200 \\
Dodecil sulfato de sódio (SDS) & 1427 \\
Acetona & 5800 \\
Hidróxido de sódio & 1350 \\
Metil isobutil cetona & 2080 \\
Álcool isoamílico & 1300 \\
Cloreto de metileno & 1500 \\
Metil isobutil cetona & 2080 \\
Dicloroetano & 670 \\
\hline
\end{tabular}

propileno recuperado do processo de extração de $\mathrm{P}(3 \mathrm{HB})$, a partir de Cupriavidus necator, na recuperação e pureza do biopolímero extraído, além de avaliar as perdas do solvente nas etapas do processo.

\section{Materiais e Métodos}

\subsection{Extração de $P(3 H B)$ com carbonato de propileno}

A biomassa de Cupriavidus necator DSM 545 com $69,0 \%$ de $\mathrm{P}(3 \mathrm{HB})$, produzida a partir de glicose, foi utilizada no presente estudo. Ao término do cultivo, as células foram separadas por centrifugação a $2.000 \mathrm{~g}$, durante 15 minutos. $\mathrm{O}$ precipitado foi lavado duas vezes com água destilada e submetido à secagem em estufa a $65^{\circ} \mathrm{C}$ por $24 \mathrm{~h}$, a fim de evitar a interferência da umidade da biomassa na recuperação do biopolímero com carbonato de propileno.

Para a recuperação do biopolímero, foi utilizado o método baseado no estudo de Quines et al. ${ }^{[7]}$, com modificações. O método baseia-se no uso de $4 \mathrm{~g}$ de células secas (balança analítica BEL Engineering) suspensas em $26 \mathrm{~mL}$ de carbonato de propileno (Sigma Aldrich com pureza de 99,7\%), aquecido a $150{ }^{\circ} \mathrm{C}$, durante 45 minutos. Os experimentos foram realizados em rotaevaporador (IKA, modelo RV 10 basic) sob agitação constante de $120 \mathrm{rpm}$.

A suspensão (carbonato de propileno, debris celulares e $\mathrm{P}(3 \mathrm{HB})$ ) obtida após o tempo de extração, foi submetida à filtração a quente sob vácuo em aparato composto por kitassato, funil de porcelana, filtro de papel qualitativo com poro de $14 \mu \mathrm{m}$ e diâmetro de $12,5 \mathrm{~cm}\left(\right.$ Qualy $\left.{ }^{\mathbb{R}}\right)$, e bomba a vácuo J. B. Industries - DV 200N 250. Os sólidos, debris celulares, retidos no filtro foram lavados com $60 \mathrm{~mL}$ de carbonato de propileno aquecido à mesma temperatura da extração. $\mathrm{O}$ filtrado contendo $\mathrm{P}(3 \mathrm{HB})$, dissolvido em solvente, permaneceu em repouso por $12 \mathrm{~h}$ à temperatura ambiente.

Após o tempo de repouso, água destilada foi adicionada em uma relação 4:1 (água:solvente com o polímero), para a precipitação do polímero, e a suspensão foi submetida à agitação constante por $12 \mathrm{~h}$. Posteriormente, a suspensão foi submetida a uma segunda filtração, nas mesmas condições que a filtração anterior, porém a temperatura ambiente. O material polimérico retido no filtro foi lavado com $200 \mathrm{~mL}$ de água destilada, e o filtro contendo a massa polimérica foi seco em estufa a $65{ }^{\circ} \mathrm{C}$ por $24 \mathrm{~h}$, obtendo-se a massa de biopolímero obtida a partir da massa inicial de células (da ordem de $4 \mathrm{~g}$ ).

\subsection{Determinação de $P(3 H B)$}

A concentração de $\mathrm{P}(3 \mathrm{HB})$ nas amostras de polímeros extraídos foi determinada por cromatografia líquida de alta eficiência (HPLC), conforme o método descrito por Karr et al. ${ }^{[20]}$. Esta análise foi realizada em um HPLC Perkin Elmer Series 200. A concentração polimérica foi detectada a $\mathrm{A}_{210 \mathrm{~nm}}$ em detector ultravioleta com fluxo de solvente $\left(\mathrm{H}_{2} \mathrm{SO}_{4} 5 \mathrm{mM}\right)$ de $0,7 \mathrm{~mL} \mathrm{~min}^{-1}$.

Para a determinação da porcentagem de pureza do P(3HB) extraído, utilizou-se a Equação 1.

$$
\text { pureza }=\frac{m_{P(3 H B)}}{m_{t}} \times 100
$$


Onde:

$m_{P(3 H B)}=$ massa de biopolímero detectada por cromatografia $(\mathrm{g})$; $m_{T}=$ massa do material extraído utilizado para a análise cromatográfica $(\mathrm{g})$.

A partir da porcentagem de pureza do $\mathrm{P}(3 \mathrm{HB})$ extraído, foi possível determinar a porcentagem de recuperação por meio da Equação 2.

$$
\text { recuperação }=\frac{m_{p}}{m_{i}} \times 100
$$

Onde:

$m_{P}=$ massa de $\mathrm{P}(3 \mathrm{HB})$ puro $(\mathrm{g})=\mathrm{m}_{\mathrm{f} *}$ pureza;

$\mathrm{m}_{\mathrm{f}}=$ massa de $\mathrm{P}(3 \mathrm{HB})$ obtido após a recuperação $(\mathrm{g})$;

$m_{I}=$ massa de $\mathrm{P}(3 \mathrm{HB})$ nas células antes da extração $(\mathrm{g})$.

\subsection{Recuperação do carbonato de propileno}

\subsubsection{Recuperação do carbonato de propileno após extração polimérica}

Visando estudar a eficiência na extração de $\mathrm{P}(3 \mathrm{HB})$ do solvente carbonato de propileno recuperado, onze extrações sequenciais (em duplicata) foram realizadas a partir de biomassa de $C$. necator, sendo que, ao término de cada extração, o solvente foi recuperado e reutilizado na extração seguinte. Foram efetuados onze ensaios sequenciais de extração de $\mathrm{P}(3 \mathrm{HB})$ com carbonato de propileno e, consequentemente, onze testes de recuperação de solvente. Cumpre destacar que, para a obtenção do mesmo volume de solvente utilizado na primeira extração, adicionou-se solvente não utilizado a fim de completar o volume de $86 \mathrm{~mL}$.

Ao final do processo de extração de $\mathrm{P}(3 \mathrm{HB})$, após a segunda filtração, obteve-se uma mistura de carbonato de propileno, água e outros componentes celulares solúveis (lipídios, proteínas e ácidos nucleicos). Para que houvesse a separação da água do solvente, a mistura obtida foi aquecida em banho a $90{ }^{\circ} \mathrm{C}$, acoplado a um evaporador rotativo (IKA RV 10 basic) a vácuo, utilizando-se uma bomba a vácuo (J. B. Industries - DV 200N 250) durante 60 minutos. Este tratamento provocou a evaporação da água, permanecendo no balão somente carbonato de propileno e impurezas solúveis residuais das células (como lipídios).

Para a determinação do rendimento da recuperação do carbonato de propileno, após a extração polimérica, foi utilizada a Equação 3.

$$
R s=\left(\frac{V_{r}}{V_{i}}\right) \times 100
$$

Onde:

Rs $=$ Rendimento de recuperação de solvente após extração (\%);

$\mathrm{V}_{\mathrm{i}}=$ Volume de carbonato de propileno utilizado na extração $(\mathrm{mL})$;

$\mathrm{V}_{\mathrm{r}}=$ Volume de carbonato de propileno recuperado $(\mathrm{mL})$.

A porcentagem de perda de solvente no processo de extração de $\mathrm{P}(3 \mathrm{HB})$ (Ppex (\%)) pode ser obtida a partir da Equação 4.

$$
\text { Ppex }=100-R s
$$

Onde:

Ppex $=$ Perda de solvente no processo de extração de $\mathrm{P}(3 \mathrm{HB})(\%)$

A eficiência da reutilização do solvente no processo de extração de $\mathrm{P}(3 \mathrm{HB})$ foi definida com a comparação dos resultados de pureza e recuperação das extrações realizadas com solvente recuperado, com os resultados obtidos a partir da extração com solvente puro (utilizado pela primeira vez).

Para a obtenção do mesmo volume de solvente utilizado na primeira extração, foi calculado o make-up do processo, que é o valor equivalente ao volume de solvente perdido no processo de extração (Equação 5).

$$
V_{A}=V_{i}-V_{r}
$$

Onde:

$\mathrm{V}_{\mathrm{A}}=$ Volume de carbonato de propileno puro a ser adicionado a cada nova extração com solvente recuperado (make-up) $(\mathrm{mL})$; $\mathrm{V}_{\mathrm{i}}=$ Volume de carbonato de propileno utilizado na extração $(\mathrm{mL})$;

$\mathrm{V}_{\mathrm{r}}=$ Volume de carbonato de propileno recuperado $(\mathrm{mL})$.

\subsubsection{Recuperação do carbonato de propileno puro (controle)}

Para quantificar possíveis perdas de carbonato de propileno, apenas durante o processo de recuperação do solvente, foram realizados testes de recuperação (controle) com volumes conhecidos de carbonato de propileno puro e de água destilada, no qual o mesmo volume de solvente utilizado na extração foi misturado ao mesmo volume de água (utilizada para precipitação e lavagem do $\mathrm{P}(3 \mathrm{HB})$ ). Assim, para separar a água do solvente, a mistura foi aquecida em evaporador rotativo conforme descrito no item 2.3.1. $\mathrm{O}$ rendimento de recuperação de solvente (controle) (Rsp (\%)) foi calculado a partir da Equação 3.

Para a obtenção da porcentagem de perda de solvente apenas na etapa de recuperação do mesmo (Psp (\%)) (separação da água do solvente por evaporação), foi utilizada a Equação 6.

$$
P s p=100-R s p
$$

Onde:

Psp $=$ Perda de solvente apenas na etapa de recuperação do mesmo (\%);

Rsp $=$ Rendimento de recuperação de solvente (controle) (\%).

\subsubsection{Recuperação do carbonato de propileno após etapas de} filtração na extração de $\mathrm{P}(3 \mathrm{HB})$

Visando quantificar possíveis perdas de carbonato de propileno durante as etapas de filtração do processo de extração de $\mathrm{P}(3 \mathrm{HB})$ com carbonato de propileno, e perdas de solvente retido nas células após a primeira filtração, foram realizados testes onde uma massa de $\mathrm{P}(3 \mathrm{HB})$ comercial, PHB industrial, de 2,76 g (massa baseada nos ensaios de extração, pois foram utilizadas $4 \mathrm{~g}$ de biomassa com $69,0 \%$ de $\mathrm{P}(3 \mathrm{HB})$ ), foi misturada ao mesmo volume de solvente utilizado na etapa de extração $(26 \mathrm{~mL})$ aquecido a $150{ }^{\circ} \mathrm{C}$ durante 45 minutos. Posteriormente, foi realizada a primeira 
filtração, empregando-se o mesmo volume de solvente utilizado para lavagem dos resíduos celulares retidos $(60 \mathrm{~mL})$, em seguida realizou-se a adição de água destilada (mesmo volume utilizado na extração) para precipitação polimérica e, por fim, a segunda filtração para a separação do polímero da solução formada por água e solvente. Para separar a água do solvente, a mistura foi aquecida em evaporador rotativo conforme descrito no item 2.3.1. O rendimento de recuperação de solvente após as etapas de filtração $(\operatorname{Rf}(\%))$ foi calculado a partir da Equação 3.

A perda de solvente nas etapas de filtração do processo de extração de $\mathrm{P}(3 \mathrm{HB})(\mathrm{Pf}(\%))$ foi determinada a partir da Equação 7.

$$
P f=100-P s p-R f
$$

Onde:

$\mathrm{Pf}=$ Perda de solvente nas etapas de filtração do processo (\%); Psp $=$ Perda de solvente apenas na etapa de recuperação do mesmo (\%);

$\mathrm{Rf}=$ Rendimento de recuperação de solvente após as etapas de filtração (\%).

Com os valores de perdas de solvente nas etapas de filtração do processo, de recuperação de solvente (evaporação da água) e no processo de extração de $\mathrm{P}(3 \mathrm{HB})$ de Cupriavidus necator, pode-se obter a perda de solvente que fica aderida nas células após a primeira filtração (Pcel (\%)) (Equação 8).

$$
\text { Pcel }=\text { Ppex }-P s p-P f
$$

\subsection{Análise termogravimétrica (TGA)}

Análise termogravimétrica foi utilizada para avaliar a porcentagem de perda de massa do $\mathrm{P}(3 \mathrm{HB})$ extraído e, consequentemente, a sua porcentagem de pureza. A análise foi realizada em uma termobalança TGA-Q50/TA Instruments (Laboratório de Materiais/UNIVILLE). As amostras foram aquecidas de 25 a $400{ }^{\circ} \mathrm{C}$, em cadinhos de alumina, a uma razão de aquecimento de $10{ }^{\circ} \mathrm{C} \mathrm{min}^{-1}$, sob atmosfera de nitrogênio (fluxo de nitrogênio de $40 \mathrm{~mL} \mathrm{~min}^{-1}$ ). Esta análise foi realizada para se obter as porcentagens de pureza dos polímeros extraídos com carbonato de propileno puro, não recuperado, e com solvente recuperado 11 vezes, a partir da porcentagem da perda de massa, a fim de confirmar a pureza obtida a partir da análise de cromatografia gasosa.

\section{Resultados e Discussão}

\subsection{Recuperação do carbonato de propileno após extração polimérica}

Na Figura 1 e Tabela 2, estão apresentados os resultados de rendimentos de recuperação do carbonato de propileno nos ensaios realizados com solvente puro e com solvente reutilizado na extração de $\mathrm{P}(3 \mathrm{HB})$ de $C$. necator (ensaios realizados em duplicata).

Nota-se na Tabela 2 que nos ensaios realizados com carbonato de propileno puro, a porcentagem de recuperação ficou entre 93,8 e 96,3\% (valor médio de 94,7\%), indicando que pode ter ocorrido em média $5 \%$ de perdas de carbonato

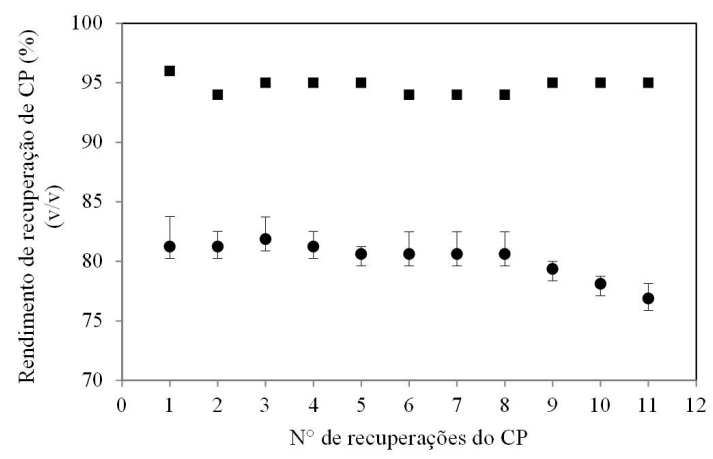

Figura 1. Resultados de rendimento de recuperação de carbonato de propileno $(\mathrm{CP})$, obtidos nos ensaios realizados com solvente puro $(\bullet)$ e com CP recuperado no processo de extração $(\bullet)$. Os dados de rendimento de recuperação de $\mathrm{CP}$ após extração do polímero correspondem a uma média de dois ensaios e os respectivos desvios médios estão representados pelas barras.

Tabela 2. Rendimento de recuperação de carbonato de propileno (CP), obtidos nos ensaios realizados com solvente puro e com $\mathrm{CP}$ recuperado no processo de extração. Ensaios de recuperação de CP após extração do polímero foram realizados em duplicata, onde os dados de rendimento de recuperação de $\mathrm{CP}$ reutilizado correspondem à média dos ensaios com os respectivos desvios médios.

\begin{tabular}{ccc}
\hline \multirow{2}{*}{$\begin{array}{c}\text { No de } \\
\text { Recuperações }\end{array}$} & \multicolumn{2}{c}{ Rendimento de Recuperação de CP (\%) } \\
\cline { 2 - 3 } & $\begin{array}{c}\text { CP recuperado na } \\
\text { extração }\end{array}$ & CP puro \\
\hline 1 & $81,2 \pm 2,5$ & 96,3 \\
2 & $81,2 \pm 1,3$ & 93,8 \\
3 & $81,9 \pm 1,9$ & 95,0 \\
4 & $81,2 \pm 1,3$ & 95,0 \\
5 & $80,5 \pm 0,6$ & 95,0 \\
6 & $80,6 \pm 1,8$ & 93,8 \\
7 & $80,6 \pm 1,9$ & 93,8 \\
8 & $80,6 \pm 1,8$ & 93,8 \\
9 & $79,4 \pm 0,6$ & 95,0 \\
10 & $78,1 \pm 0,6$ & 95,0 \\
11 & $76,9 \pm 1,3$ & 95,0 \\
\hline
\end{tabular}

de propileno no processo de recuperação. Estas perdas podem ter ocorrido devido ao arraste do solvente juntamente com a água durante a etapa de evaporação da água do processo de recuperação do solvente (confirmado nos ensaios com CP puro).

Os valores obtidos de rendimentos de recuperação de carbonato de propileno após a extração ficaram em torno de $80 \%$, com variação entre 76,9 e $82,0 \%$. É importante destacar que estes valores (Tabela 2 ) referem-se ao volume de solvente recuperado, após a extração de $\mathrm{P}(3 \mathrm{HB})$ de biomassa, constituído de componentes celulares solúveis remanescentes deste processo. De acordo com Aragão et al. ${ }^{[21]}$, a biomassa de $C$. necator é composta por $40 \%$ de proteínas, $14 \%$ de fosfolipídios, $25,6 \%$ de polissacarídeos, 5,5\% de peptidioglicano, $11 \%$ de lipídios, entre outros constituintes em menores concentrações. Alguns destes constituintes celulares, como os lipídios, por exemplo, durante o processo 
de extração do $\mathrm{P}(3 \mathrm{HB})$ das células, permanecem solubilizados no carbonato de propileno.

Na Figura 1 observa-se um decréscimo no rendimento de recuperação do carbonato de propileno, a partir da oitava recuperação. A diminuição desses valores após oito recuperações de solvente pode ter ocorrido em função das impurezas remanescentes no solvente (resíduos celulares solúveis no solvente a cada extração) e formação de uma solução (carbonato de propileno e impurezas) mais viscosa $\mathrm{e}$, consequentemente, com maior perda de solvente na etapa de extração polimérica.

Não há na literatura estudos sobre o rendimento da recuperação de carbonato de propileno após o processo de extração e nem da sua eficiência após ser reciclado. Mcchalicher et al. ${ }^{[16]}$ recuperaram carbonato de propileno, após a extração de $\mathrm{P}(3 \mathrm{HB})$, a $90{ }^{\circ} \mathrm{C}$ sob vácuo, porém não apresentaram os resultados de rendimento de recuperação de solvente e nem se o mesmo foi reutilizado no processo de extração. Lafferty e Heinzle ${ }^{[17]}$ também relataram a recuperação de carbonato de propileno, após extração de $\mathrm{P}(3 \mathrm{HB})$, e sua eficiente reutilização por três vezes. No entanto, não apresentaram resultados para esta etapa do estudo.

Os resultados dos experimentos de recuperação do solvente, considerando-se todo o processo de extração de $\mathrm{P}(3 \mathrm{HB})$ realizados, mostraram que ocorreram perdas de cerca de $20 \%$ de solvente durante o processo, sendo necessário um make-up desta porcentagem de solvente a cada extração (reposição de 17,2 mL de solvente), e a partir dos resultados de recuperação de solvente puro observa-se que 5\% destas perdas são referentes à etapa de evaporação. Para quantificar as perdas de solvente durante o processo de extração de $\mathrm{P}(3 \mathrm{HB})$, foram determinadas as porcentagens de perdas de solvente nas seguintes etapas: filtrações do processo de extração de $\mathrm{P}(3 \mathrm{HB})$ (Pf(\%) Equação 7) e perda de solvente que fica aderido nas células após a primeira filtração (Pcel (\%) Equação 8), conforme apresentado na Tabela 3.

De acordo com a Tabela 3 observa-se que as maiores porcentagens de perdas de solvente (11\%) ocorrem durante as etapas de filtração do processo de extração de $\mathrm{P}(3 \mathrm{HB})$ e cerca de $4 \%$ de solvente é perdido nos resíduos celulares na primeira filtração deste processo.

\subsection{Recuperação e pureza de $P(3 H B)$ extraído com carbonato de propileno reutilizado}

Sabe-se que a cada recuperação do solvente, após o processo de extração com carbonato de propileno, tem-se um solvente com maior concentração de componentes celulares solúveis remanescentes. Dessa maneira, essas impurezas contidas no solvente recuperado poderiam influenciar na pureza do $\mathrm{P}(3 \mathrm{HB})$ extraído com o solvente reutilizado, reduzindo a qualidade do produto final. A investigação do reuso de carbonato de propileno, após a extração de $\mathrm{P}(3 \mathrm{HB})$ nos resultados de recuperação e pureza, é de grande importância para a avaliação da eficiência deste solvente depois de repetidas reutilizações. Os resultados das duplicatas da análise de recuperação de $\mathrm{P}(3 \mathrm{HB})$, após cada extração com carbonato de propileno recuperado, estão apresentados na Tabela 4.

Pode-se observar que o carbonato de propileno mostrou-se eficiente para o processo de extração de $\mathrm{P}(3 \mathrm{HB})$, mesmo após
Tabela 3. Resultados de porcentagens de perdas de solvente nas etapas de filtração do processo de extração de $\mathrm{P}(3 \mathrm{HB})$ (Pf (\%) Equação 7) e perdas de solvente que permanece nas células após a primeira filtração (Pcel (\%) Equação 8).

\begin{tabular}{cc}
\hline Etapas do processo & Perda de solvente (\%) \\
\hline Pf & $11 \pm 0,75$ \\
Pcel & $4 \pm 0,75$ \\
\hline
\end{tabular}

Tabela 4. Resultados de recuperação e pureza de $\mathrm{P}(3 \mathrm{HB})$ nas extrações realizadas a cada recuperação do carbonato de propileno (11 vezes). Os dados correspondem a uma média de dois ensaios e os respectivos desvios médios.

\begin{tabular}{ccc}
\hline $\begin{array}{c}\text { Número de } \\
\text { recuperações do CP }\end{array}$ & $\begin{array}{c}\text { Recuperação de } \\
\mathbf{P}(\mathbf{3 H B}) \mathbf{( \% )}\end{array}$ & $\begin{array}{c}\text { Pureza do P(3HB) } \\
\mathbf{( \% )}\end{array}$ \\
\hline 0 & $74,3 \pm 0,8$ & $97,9 \pm 1,0$ \\
1 & $75,8 \pm 0,2$ & $92,6 \pm 3,0$ \\
2 & $77,1 \pm 0,2$ & $92,0 \pm 0,4$ \\
3 & $76,5 \pm 0,7$ & $98,8 \pm 0,2$ \\
4 & $74,9 \pm 0,9$ & $91,3 \pm 1,4$ \\
5 & $75,1 \pm 1,3$ & $94,8 \pm 2,1$ \\
6 & $74,2 \pm 0,9$ & $95,1 \pm 2,9$ \\
7 & $75,0 \pm 1,6$ & $99,0 \pm 0$ \\
8 & $73,0 \pm 1,5$ & $92,1 \pm 0,3$ \\
9 & $73,7 \pm 1,2$ & $91,3 \pm 0,1$ \\
10 & $73,6 \pm 1,0$ & $91,2 \pm 0,1$ \\
11 & $77,0 \pm 1,3$ & $99,0 \pm 0$ \\
Valor médio & $75,0 \pm 1,0$ & $94,6 \pm 2,8$ \\
\hline
\end{tabular}

onze recuperações sucessivas. Os percentuais de recuperação de $\mathrm{P}(3 \mathrm{HB})$, com carbonato de propileno recuperado após cada extração, mantiveram-se praticamente constantes e ficaram entre 73,0 e 77,0\% (valor médio de 75,0\%). As diferenças observadas entre os resultados de recuperação de $\mathrm{P}(3 \mathrm{HB})$ com solvente reutilizado podem estar relacionadas às perdas de polímero que ocorreram durante o processo de extração, uma vez que este envolve diversas operações unitárias.

Os valores de pureza para os polímeros extraídos com carbonato de propileno, reciclado até 11 vezes, mantiveram-se entre 91,2 e 99,0\% (valor médio de 94,6\%). As diferenças observadas nas porcentagens de pureza dos polímeros extraídos com solvente reciclado se devem, provavelmente, a erros experimentais e não apresentam relação direta com o número de vezes que o solvente utilizado para a extração foi recuperado.

Com o objetivo de confirmar a pureza do polímero extraído (determinada em HPLC) com carbonato de propileno recuperado foi realizada análise termogravimétrica (TGA) das amostras de polímero extraídas com este solvente recuperado onze vezes e com carbonato de propileno puro (não recuperado). A análise de TGA fornece o perfil de degradação térmica de polímeros, as temperaturas de degradação e a partir da variação de massa em função da temperatura, perda de massa, a obtenção da pureza do biopolímero, pois a parte degradada se refere ao material polimérico e a não degradada às impurezas inorgânicas presentes na amostra ${ }^{[22]}$

As curvas de perda de massa mostradas na Figura 2 representam a degradação das amostras de $\mathrm{P}(3 \mathrm{HB})$ extraído com carbonato de propileno puro (não reutilizado) e com 


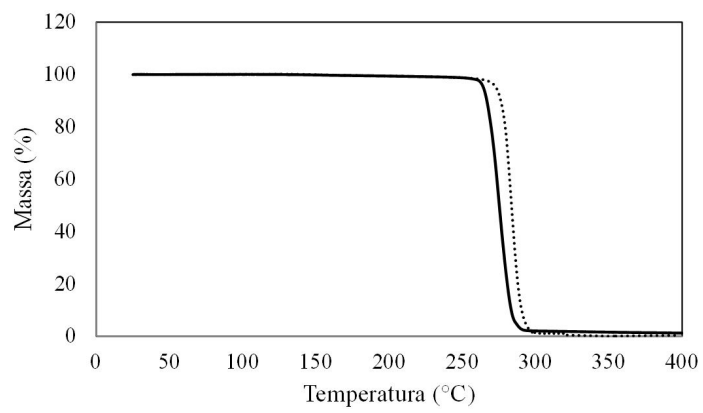

Figura 2. Termogramas de TGA para $\mathrm{P}(3 \mathrm{HB})$ extraído com $\mathrm{CP}$ puro (não reutilizado) (-) e para $\mathrm{P}(3 \mathrm{HB})$ extraído com $\mathrm{CP}$ reutilizado 11 vezes $(\cdots)$.

carbonato de propileno reutilizado 11 vezes, sob aquecimento de 25 a $400{ }^{\circ} \mathrm{C}$, sendo que, a parte não degradada refere-se às impurezas do polímero e a parte degradada ao material polimérico (\% pureza).

Os resultados de pureza obtidos pela análise de TGA para as amostras de polímero extraídas com solvente puro e com o solvente reutilizado onze vezes foram de 97,4 e $98,8 \%$, respectivamente. As porcentagens de pureza determinadas para estas mesmas amostras de $\mathrm{P}(3 \mathrm{HB})$ por HPLC (Tabela 4) foram de $97,9 \%$ (solvente puro) e $99,0 \%$ (solvente onze vezes recuperado), confirmando assim elevada pureza obtida para a amostra de $\mathrm{P}(3 \mathrm{HB})$ extraída de $C$. necator com carbonato de propileno reutilizado onze vezes.

Esses resultados mostram a importância da utilização de carbonato de propileno na extração de $\mathrm{P}(3 \mathrm{HB})$, pois, além de ser um solvente de baixa toxicidade, pode ser reutilizado no processo em até, pelo menos, onze vezes sem perder a eficiência na recuperação polimérica e sem influenciar na pureza dos polímeros extraídos. Os resultados obtidos nesse estudo são importantes do ponto de vista tecnológico, uma vez que foi explorada a reutilização de um solvente de baixa toxicidade para extração de um biopolímero, produzido a partir de fonte renovável de carbono, e ao final do processo foi possível a obtenção de um produto com elevada pureza. Essa última característica é importante, pois a pureza do bioproduto extraído é de grande relevância para o direcionamento e adequação deste polímero em futuras aplicações.

\section{Conclusões}

Quando o carbonato de propileno, após a extração do $\mathrm{P}(3 \mathrm{HB})$, foi submetido à recuperação obteve-se rendimento de $80 \%$ de solvente, evidenciando que ocorrem perdas de solvente nas etapas do processo de extração com a necessidade de make-up de $20 \%$ de solvente a cada nova extração. Sendo que dos $20 \%$ de carbonato de propileno não recuperado, $5 \%$ é referente à perda de solvente na evaporação da água, $11 \%$ proveniente de perdas nas etapas de filltração e $4 \%$ de perdas por aderência do solvente nos resíduos celulares.

A reutilização do carbonato de propileno no processo de extração de $\mathrm{P}(3 \mathrm{HB})$ de Cupriavidus necator mostrou-se eficiente, após onze recuperações. Confirmando a possibilidade de reciclo do carbonato de propileno na extração de
$\mathrm{P}(3 \mathrm{HB})$, sem redução na sua eficiência como solvente para recuperação de biopolímero com elevada pureza. Nesse sentido, os resultados obtidos nesse trabalho têm relevância tecnológica e podem contribuir para o avanço da utilização de carbonato de propileno na extração de $\mathrm{P}(3 \mathrm{HB})$, visto que este solvente, mesmo apresentando elevado custo, pode facilmente ser recuperado após o processo de extração polimérica e reutilizado, neste mesmo processo, várias vezes sem influenciar nos resultados de pureza e recuperação do polímero extraído.

\section{Referências}

1. Anderson, A. J., \& Dawes, E. A. (1990). Occurrence, metabolism, metabolic role and industrial uses of bacterial polyhydroxyalkanoates. Microbiology Reviews, 54(4), 450472. http://dx.doi.org/0146-0749/90/040450-23.

2. Khanna, S., \& Srivastava, A. K. (2004). Recent advances in microbial polyhydroxyalkanoates. Process Biochemistry, 40(2), 607-619. http://dx.doi.org/10.1016/j.procbio.2004.01.053.

3. Madkour, M. H., Heinrich, D., Alghamdi, M. A., Shabbaj, I. I., \& Steinbüchel, A. (2013). PHA recovery from biomass. Biomacromolecules, 14(9), 2963-2972. PMid:23875914. http:// dx.doi.org/10.1021/bm4010244.

4. Silva, L. F., Gomez, J. G. C., Rocha, R. C. S., Taciro, M. K., \& Pradella, J. G. C. (2007). Produção biotecnológica de polihidroxialcanoatos para a geração de polímeros biodegradáveis no Brasil. Quimica Nova, 30(7), 1732-1743. http://dx.doi org/10.1590/S0100-40422007000700040.

5. Kshirsagar, P. R., Kulkarni, S. O., Nilegaonkar, S. S., Niveditha, M., \& Kanekar, P. P. (2013). Kinetics and model building for recovery of polyhydroxyalkanoate (PHA) from Halomonas campisalis. Separation and Purification Technology, 130, 151-160. http://dx.doi.org/10.1016/j.seppur.2012.10.007.

6. Fiorese, M. L., Freitas, F., Pais, J., Ramos, A. M., Aragão, G. M. F., \& Reis, M. A. M. (2009). Recovery of polyhydroxybutyrate (PHB) from Cupriavidus necator biomass by solvent extraction with 1,2-propylene carbonate. Engineering in Life Sciences, 9(6), 454-461.http://dx.doi.org/10.1002/elsc.200900034.

7. Quines, L. K. M., Ienczak, J. L., Schmidt, M., Zanfonato, K., Rodrigues, M. I., Schmidell, W., \& Aragão, G. M. F. (2015). Extração de poli(3-hidroxibutirato), produzido por Cupriavidus necator, com carbonato de propileno. Quimica Nova, 38(2), 214-220. http://dx.doi.org/10.5935/0100-4042.20140297.

8. Ramsay, J. A., Berger, E., Voyer, R., Chavarie, C., \& Ramsay, B. A. (1994). Extraction of poli-3-hydroxybutyrate using chlorinated solvents. Biotechnology Techniques, 8(8), 589-594. http://dx.doi.org/10.1007/BF00152152.

9. Neves, A., \& Müller, J. (2012). Use of enzymes in extraction of polyhydroxyalkanoates produced by Cupriavidus necator. Biotechnology Progress, 28(6), 1575-1580. PMid:22915526. http://dx.doi.org/10.1002/btpr.1624.

10. Martino, L. L., Cruz, M. V., Scomac, A., Freitas, F., Bertin, L., Scandola, M., \& Reis, M. A. M. (2014). Recovery of amorphous polyhydroxybutyrate granules from Cupriavidus necator cells grown on used cooking oil. Journal of Biological Macromolecules, 71, 117-123. PMid:24751509.http://dx.doi. org/10.1016/j.ijbiomac.2014.04.016.

11. Tamer, I. M., Moo-Young, M., \& Chist, Y. (1998). Optimization of poly(beta-hydroxybutyric acid) recovery from Alcaligenes latus: combined mechanical and chemical treatments. Bioprocess Engineering, 19(6), 459-468. http://dx.doi.org/10. 1007/ PL00009030.

12. Van Hee, P., Middelberg, A. P. J., Van Der, L. R. G. J. M., \& Van Der, W. L. A. M. (2004). Relation between cell disruption 
conditions, cell debris particle size, and inclusion body release. Biotechnology and Bioengineering, 88(1), 100-110. PMid:15449302. http://dx.doi.org/10.1002/bit.20343.

13. Chen, Y., Yang, H., Zhou, Q., Chen, J., \& Gu, G. (2001). Cleaner recovery of poly(3-hydroxy-butyric acid) synthesized in Alcaligenes eutrophus. Process Biochemistry, 36(6), 501506. http://dx.doi.org/10.1016/S0032-9592(00)00225-9.

14. Jiang, Y., Mikova, G., Kleerebezem, R., Wielen, L. A. M., \& Cuellar, M. C. (2015). Feasibility study of an alkaline based chemical treatment for the purification of polyhydroxybutyrate produced by a mixed enriched culture. AMB Express, 5(1), 1-13. PMid:25642402. http://dx.doi.org/10.1186/s13568-0150096-5.

15. Riedel, S. L., Brigham, C. J., Budde, C. F., Bader, J., Rha, C., Stahl, U., \& Sinskey, A. J. (2013). Recovery of poly(3hydroxybutyrate-co-3-hydroxyhexanoate) from Ralstonia eutrophacultures with non-halogenated solvents. Biotechnology and Bioengineering, 110(2), 461-470. PMid:22903730. http:// dx.doi.org/10.1002/bit.24713.

16. Mcchalicher, C. W. J., Srienc, F., \& Rouse, D. P. (2009). Solubility and degradation of polyhydroxyalkanoate biopolymers in propylene carbonate. American Institute of Chemical Engineers, 56(6), 1616-1625. http://dx.doi.org/10.1002/aic.12087.

17. Lafferty, R. M., \& Heinsle, E. (1979). U.S. Patent No 4.140.741. Use of ciclyc carbonic acid esters as solvents for poly-( $\beta$ hidroxybutyric acid).Washington: U.S. Patent and Trademark Office.
18. Cosmetic Ingredient Review - CIR. (1987). Final report on the assessment of propylene carbonate. Journal of the American College of Toxicology, 6(1), 23-51. http://dx.doi. org/10.3109/10915818709095488.

19. Environmental Protection Agency. (1998). Environmental profile for propylene carbonate (pp. 1-52). Cincinnati: United States Environmental Protection Agency. Recuperado em 19 de março de 2015, de http://nepis.epa.gov

20. Karr, D. B., Waters, J. K., \& Emerich, D. W. (1983). Analysis of Poly-3-Hydroxybutyrate in Rhizobium japonicum Bacteroids by ion-exclusion high-pressure liquid chromatography and UV detectiont. Applied and Environmental Microbiology, 46(6), 1339-1344. PMid:16346443.

21. Aragão, G. M. F., Lindley, N. D., Uribelarrea, J. L., \& Pareilleux, A. (1996). Maintaining a controlled residual growth capacity increases the production of polyhydroxyalkanoate copolymers by Alcaligenes eutrophus. Biotechnology Letters, 18(8), 937942. http://dx.doi.org/10.1007/BF00154625.

22. Canevarolo, S. V. (2007). Técnicas de caracterização de polímeros. São Paulo: ARTLIBER. 444 p.

Enviado: Mar. 19, 2015

Revisado: Jul. 31, 2015

Aceito: Jan. 27, 2016 